\title{
Materialismo no singular ou no plural
}

\author{
Michel Delon \\ Universidade de Paris l-Sorbonne
}

Tradução: Maria das Graças de Souza 

Durante muito tempo, o materialismo de Diderot foi uma questão polêmica, porque a categoria parecia, para alguns, monopolizada pela tradição marxista, que distinguia entre um materialismo mecanicista, contaminado ainda de metafísica e ilustrado pelos autores franceses do século XVIII, e um materialismo dialético e histórico, que seria o acabamento, nos séculos XIX e XX, das intuições das Luzes. O primeiro não teria sido senão uma prefiguração desajeitada do segundo. Assim, Henri Lefebvre, em 1949, encontrava em Diderot, prisioneiro de pesos e inércias idealistas, o esboço ou o pressentimento do materialismo ulterior, realmente dinâmico1. Os que quiseram libertar o autor do Sonho de d'Alembert desta vulgata marxista procuraram, por sua vez, caracterizar seu materialismo com um adjetivo. Yvon Belaval diz que se trata de um materialismo vitalo-químico, ou químico-vitalista, para associá-lo aos desenvolvimentos científicos do tempo e melhor opô-lo ao "materialismo artesanal" de um La Mettrie ou de um Helvétius, "que maquina os organismos e os submete ao hábito" (Belaval, 1967/2003), variante do materialismo mecanicista ${ }^{2}$. Vinte anos mais tarde, Elisabeth de Fontenay fala de um "materialismo encantado", materialismo libertário e poético, contra todas as filosofias autoritárias e disciplinares³. Mais recentemente, sem temer a referência a uma categoria que só aparecerá, sob a pluma de Lamarck, uma vintena de anos após a morte de Diderot, se disse que seu materialismo é biológico, preocupado em explicar o aparecimento da vida na matéria, levando em conta os avanços das ciências da vida contemporâneas4. Mais recentemente ainda, Annie Ibrahim o julgou "eclético"s em ligação com o elogio que Diderot propõe, na Enciclopédia, de uma abordagem eclética, quer dizer, crítica, atenta às contradições da realidade.

\footnotetext{
1 Cf. Lefebvre, $1949 / 1983$.

2 Ver Suratteau-Iberrakens, 1999.

3 Cf. Fontenay, 1981.

4 Cf. Lojkine, 1994.

5 Cf. Ibrahim, 2010.
} 
Jean-Claude Bourdin teria sido tentado a falar de um materialismo cético, mas a esta busca de um epíteto característico de um sistema filosófico preferiu o estudo de um filósofo materialista decididamente poeta, que recusa toda síntese para multiplicar as imagens e as formas de intervenção ${ }^{6}$. Diderot seria materialista, mais do que partidário de um materialismo particular, senão talvez mesmo de um materialismo poético.

A escolha de um adjetivo manifesta sem dúvida um gosto louvável pela nuance e pela precisão, mas corresponde a uma vontade de etiquetar que é igualmente sensível no debate sobre a evolução do jovem Diderot. Deve-se pensar nos anos de formação como busca de uma posição pessoal que o faria passar do deísmo ao ateísmo e do ceticismo ao materialismo? Franco Venturi assinalara que todos estes termos são abstrações, estranhas à realidade do trabalho intelectual de Diderot (Venturi, 1939, p. 12). Eles reduzem situações de enunciação particulares e experiências teóricas inventivas a categorias gerais. $\mathrm{O}$ jovem, que renunciou aos estudos de teologia, recusa a ideia de criação ex nihilo e de finalidade, mostra-se cada vez mais sensível à diversidade da experiência e à natureza multicolor do real, não crê mais nas identidades fixas, e sim nas metamorfoses incessantes que transformam os seres. O racionalismo e as ideias inatas dão lugar ao empirismo e aos tateios do espírito que procuram recorrências e tendências que permitam enunciar leis. Essa consciência do estilhaçamento do real e da dispersão dos saberes governa o empreendimento enciclopédico. São recrutados especialistas em cada domínio de competência, enquanto d'Alembert e Diderot reservam para si a tarefa de construir o quadro teórico e histórico no qual os verbetes, por mais dispersos que sejam, assumem um lugar e um sentido. Eles esboçam uma história dos progressos do espírito e propõem um esquema dos conhecimentos. Diderot insiste na circulação 
que faz com que se passe de um verbete a outro e abre a Enciclopédia para uma multiplicidade de leituras e de apropriações pessoais. Os domínios aos quais cada chamada está vinculada e as remissões de uma chamada à outra são ao mesmo tempo um jogo de esconde-esconde com a censura, método de ampliação do ponto de vista e abertura para efeitos imprevistos. De um lado, um Prospecto e um Discurso Preliminar que apresentam um quadro unificador, de outro, a justaposição de verbetes que podem ser divergentes, às vezes mesmo contraditórios, e que arrastam o leitor numa exercício de comparação e de crítica. Os volumes impressos abrem-se para uma infinidade de itinerários e de extrapolações. O empirismo encontrou sua forma privilegiada no gênero dicionário, que fornece as informações sem o dever de oferecer síntese. Diderot, que postula o papel do acaso na aparição da vida e da inteligência no meio da matéria, sabe jogar com o arbitrário léxico e as sugestões do significante. Por exemplo, a aproximação fonética entre résonner (ressoar) e raisonner (raciocinar) remete à comparação entre uma física de cordas vibrantes e uma fisiologia das fibras cerebrais, entre o contíguo e o contínuo, na passagem da justaposição das células à constituição do indivíduo. Dois jogos de palavras resumem o devir de uma matéria que se torna viva, de uma vida que se torna inteligente.

O conjunto da obra de Diderot permanece aberto às solicitações da vida e se adapta à atualidade. Ela se exprime em formas abertas, dialógicas, contraditórias. A censura e a ameaça da repressão repartem a obra entre formas diferentes de publicação, autorizada ou aceita, de difusão manuscrita ou clandestinidade quase total, textos pessoais e contribuição para obras coletivas ou assinadas por outros. Não poderia se tratar de enunciar um sistema materialista no sentido em que o ateliê do Barão d'Holbach propõe um sistema da natureza: o Sistema da natureza, em 1770, faz a escolha de uma construção metódica e uma impressão clandestina sob o nome de Jean-Baptiste Mirabeau, morto dez anos antes. Diderot, sem dúvida, participou de sua redação e admira a 
sua construção, mas, de sua parte, ele se engaja num trabalho que imita uma matéria ou uma natureza em movimento sem início nem fim. Exibe a escrita como reescrita e como diálogo, metamorfose de textos preexistentes oferecida às manipulações do leitor. A colaboração com a Correspondência Literária de Melchior Grimm lhe dá o exemplo de um escritório de cópias no qual cada exemplar do periódico, entrega após entrega, pode ser adaptado ao assinante principesco. Então se dissipam as ilusões de originalidade, da criação, do indivíduo autônomo, do sujeito mestre de si. A partir desse modelo, o filósofo multiplica as intervenções, nas quais ele se interessa por todos os domínios, das ciências às belas artes, da moral à política.

Em seu primeiro livro pessoal, os Pensamentos filosóficos, ele diferencia um grande número de posições filosóficas, sem se identificar com nenhuma delas, para melhor assediar todo dogmatismo, em particular o dos teólogos cristãos. Teístas, deístas, céticos, ateus, representam desvios em relação à norma cristã, e recusam qualquer amálgama simplificador. A descontinuidade dos pensamentos, enumerados segundo uma ordem que comporta talvez uma parte do acaso, corresponde a essa mobilidade do ponto de vista. Nenhuma polícia pode assinalar ao filósofo uma tomada de posição a respeito da qual ele teria de prestar contas. A partir da Carta sobre os cegos, a hipótese que é mais frequentemente desenvolvida é materialista e ateísta. Ela permanece uma hipótese, suspensa entre a constatação da diversidade, da variedade irredutível das coisas e dos seres e a postulação tanto poética quanto filosófica de uma unidade de tudo, ou do todo. A passagem da diversidade à totalidade é também uma diferença de ponto de vista. A frequentação dos salões de pintura ajuda Diderot a formular esta mudança de base: "Aproximai-vos, tudo se confunde, se apequena, desaparece. Afastai-vos, tudo se cria e se reproduz." (Diderot, 2008, p. 83). O verbete "Visão", da Enciclopédia, oferece uma variação fisiológica desta acomodação que experimenta uma diferença de distância entre o observador e o objeto: 
De onde vem que os velhos veem de longe e deixam de ver distintamente de perto? Acabamos de dar a razão disto; entretanto, esta visão longa dos velhos não procede somente da diminuição ou do achatamento dos humores do olho, mas depende também de uma mudança de posição das partes do olho, como entre a córnea e o cristalino, ou bem entre o humor vítreo e a retina (Encyclopédie, XVII, p. 344).

Dois motivos permitem seguir, através da obra de Diderot, a exigência de atenção ao detalhe, à infinita diferença, e a necessidade, não menos imperiosa, de unidade de significação. O primeiro se liga ao princípio leibniziano dos indiscerníveis. Diderot, no verbete "Ecletismo", da Enciclopédia, defende a ideia de uma diferença que define cada indivíduo, estritamente insubstituível.

Em toda a série de indivíduos da espécie humana que existiram e que existirão, é impossível que haja dois que se assemelhem perfeitamente; donde se segue, para aqueles que sabem raciocinar, que todas as vezes que uma descoberta útil ligada à diferença específica que distinguia tal indivíduo de todos os outros, e que o constituía como tal, não tiver sido feita, ou não tiver sido publicada, ela não o será mais; é coisa perdida para o progresso das Ciências e das Artes e para a felicidade e a glória da espécie. (Id., V, p. 284)

No verbete “Leibnizianismo”, a proposição é atribuída a Leibniz, e, antes dele, aos estoicos:

Não há na natureza um só ser que seja absolutamente igual e semelhante a outro, de modo que não é possível reconhecer uma diferença interna aplicável a alguma coisa de interna. Talvez não haja nada menos razoável do que este princípio, para aqueles que só pensam superficialmente, e nada mais verdadeiro para os outros. Isto não é novo: era uma das opiniões dos estoicos. (Id., IX, p. 34)

Encontraremos proposições similares na Recherche de la 
vérité, 7 onde Malebranche considera essa infinita diversidade como uma prova do infinito poder do Criador e como causa dos erros daqueles que se limitam a uma observação superficial. Diderot inverte esta perspectiva. O que ilustrava a imensidão de Deus em Malebranche ou em Leibniz torna-se para ele a prova da aproximação de todas nossas generalizações e do perigo das abstrações $^{8}$. O princípio de ordem providencial se transforma em suspeição de uma desordem generalizada. A organização não é senão local e momentânea. Diderot reduz até mesmo os termos abstratos a aproximações que postulam uma equivalência entre experiências radicalmente diferentes, ou seja, a quiproquós mais ou menos bem controlados. O filósofo, homem das generalidades, é condenado ele também à aproximação; ele a encontra num desvio suscetível de dar uma força sugestiva ao seu propósito na imagem literária.

Na quarta carta a Clarke, publicada em 1717, Leibniz toma o exemplo de duas folhas ou duas gotas d'água que não podem ser perfeitamente semelhantes Nos Pensamentos sobre a interpretação da natureza, em 1754, Diderot dá precisão a uma nova imagem: "sobre toda árvore não haveria duas folhas sensivelmente do mesmo verde", e a desenvolve:

Talvez nunca tenha havido, e talvez nunca haverá, na natureza, dois fios de erva absolutamente do mesmo verde. Se os seres se alteram sucessivamente passando por nuances quase imperceptíveis, o tempo, que não para, deve, a longo prazo, entre as formas que existiram desde muito antigamente, aquelas que existem hoje, e aquelas que existirão

7 "É certo que todos os corpos naturais, mesmo aqueles que chamamos da mesma espécie, diferem uns dos outros, que o ouro não é perfeitamente semelhante ao ouro, e que uma gota d'água é diferente de outra gota d'água. Acontece com todos os corpos o mesmo que acontece com os rostos. Todos os rostos têm dois olhos, um nariz, uma boca, e todos são rostos, rostos de homens; e entretanto, pode-se dizer que nunca houve dois rostos absolutamente semelhantes" (Livro III, Segunda parte. Cap. X, Paris, Pralrd, 1678 , p. 219).

8 Claire Fauvergue (2006, p. 22) fala de uma "verdadeira generalização materialista”. 
nos séculos longínquos, colocar a maior diferença. (Diderot, 1975, IX, p. 91-92)

A diferença não é mais apenas topológica, ela é também temporal, ao sabor de um devir imprevisto. Entre uma afirmação e outra, Diderot passa do advérbio sensivelmente, que remete à experiência sensorial, ao advérbio absolutamente, que supõe uma abstração filosófica. Ele concebe a natureza como uma realidade infinitamente variada, em incessante transformação. O princípio dos indiscerníveis torna-se princípio de mutabilidade. Mas o desdobramento ininterrupto pode remeter a um protótipo: "Parece que a natureza tenha gostado de variar o mesmo mecanismo de uma infinidade de maneiras diferentes" (Id., ibid, 1975, IX, p. 36). No Ensaio sobre os reinos de Cláudio e Nero, que se apresenta como uma introdução à leitura de Sêneca, Diderot comenta a carta 65 a Lucilius. As gotas d'água transformam-se num rio, que é também o rio do tempo: "Vê-se aqui que o sistema do otimismo não é de ontem, e que o sistema dos indiscerníveis era conhecido desde os tempos do provérbio segundo o qual não nos banhamos duas vezes no mesmo rio, e que o homem e o rio mudaram (Diderot, Id., ibid, p. 275)9.

A cor das folhas conduz a um olhar estético. Os Ensaios sobre a pintura criticam os pintores que empobrecem a realidade, que a reduzem a um modelo, ou a um estilo: "Aqui é como a folha de uma árvore; não há nenhuma que seja do mesmo verde, nenhum destes indivíduos que seja o mesmo, na ação e na posição" (Diderot, 2008, p. 210). Mesmo aqueles que procuram apagar sua individualidade em nome de um ideal que os ultrapassa, permanecem irredutíveis uns aos outros: "Na missa, ou nas vésperas, no

9 Naigeon nota também no volume consagrado às Cartas a Lucilio, das Obras de Sêneca o filósofo, traduzidas em francês pelo senhor Lagrange: "Vê-se por esta passagem que o sistema do otimismo é muito mais antigo do que Leibniz" (Paris, ano III, t. II, p. 289), mas o princípio dos indiscerníveis parece ser obsessão própria de Diderot. 
convento dos Cartuxos, veem-se, sobre duas longas linhas paralelas, quarenta a cinquenta homens, mesmas cadeiras, mesmas funções, mesma roupa, e entretanto, não há dois destes monges que se assemelhem" (Diderot, 2008, p. 175). A observação vale também no feminino, para as jovens religiosas que Susanne Simonin descobre em volta da superiora de Santo Eutrópío: “Umas eram louras, outras morenas: nenhuma se parecia com a outra, embora fossem todas belas" (Id., ibid., p. 351). Poder-se ia acrescentar: embora vestissem o mesmo hábito e fossem submetidas à mesma regra. O grande escritor é aquele que sabe restituir esta diversidade tão bem quanto o grande pintor. É o caso de Richardson, cujo elogio Diderot compõe e cuja Clarisse Harlowe ele celebra: "Neste livro imortal, assim como na natureza na primavera, não se encontram duas folhas que sejam do mesmo verde. Que imensa variedade de nuances!". A imagem colorida se aprofunda num detalhe, numa luminosidade de um decor. Uma longa digressão do Salão de 1767 associa o princípio dos indiscerníveis à questão da expressão. As línguas são pobres, a "penúria de palavras" apaga as nuances, reduz a diversidade, mas a variedade dos acentos oferece a cada um sua própria língua, suscetível de restituir todas as diferenças individuais.

Nunca, desde que o mundo é mundo, dois amantes disseram de modo idêntico: eu te amo. E na eternidade que resta para durar, nunca duas mulheres responderam identicamente: tu és amado. Desde que Zaíra está em cena, Orosmane não disse e não dirá duas vezes de modo idêntico: Zaíra, tu estás chorando. Isso é duro de afirmar... e de crer..., mas nem por isso é menos verdadeiro. É a tese dos dois grãos de areia de Leibniz. (Id., ibid., p. 312)

O sábio materialista poderia reduzir o amor a uma pulsão idêntica em todos os seres humanos e mesmo em todos os seres vivos; o filósofo poeta reconhece o irredutível acento individual na sinfonia do mundo. A continuidade entre o grão de areia e o 
grão da voz parece desencantar o mundo; é o mundo natural que é reencantado pela riqueza do mundo moral.

O Sistema da natureza do Barão d'Holbach associa, desde o seu segundo capítulo, a heterogeneidade da matéria ao movimento que lhe é intrínseco: "Entre os indivíduos que conhecemos, numa mesma espécie, não há nenhum que se pareça exatamente com o outro e isto deve ser assim". Uma nota precisa: "Aqueles que observaram a natureza de perto, sabem que dois grãos de areia não são de modo algum estritamente iguais [...] Esta verdade é muito bem sentida pelo profundo e sutil Leibniz" (D'Holbach, 1770, I, cap. 2). Talvez Diderot tenha escrito essa página, enquanto fazia o comentário do Salão de 1767 . Em todo caso, é muito verossímil que ele a tenha lido em manuscrito. O que é que a separa da página do Salão de 1767? D’Holbach expõe a heterogeneidade da matéria com um propósito homogêneo, sistemático, Diderot torna sensível a diversidade do mundo numa miríade colorida de formas e estilos. O coletivo que escreveu anonimamente o Sistema da natureza apaga toda individualidade do autor que Diderot explora e exibe em seus próprios textos. Um proclama a força criadora da matéria e faz dela uma verdade filosófica, o outro a ilustra por meio de seu trabalho, sem separar a filosofia geral da reflexão estética. Toda tese abstrata é associada a uma situação de discurso e a uma imagem. A tese de heterogeneidade motriz da matéria reaparece em 1769 no Sonho de d'Alembert. D'Alembert desenvolve em sonho a ideia lançada por Diderot na noite da véspera; de uma proposição teórica ele faz uma visão:

Tudo muda, tudo passa, só o todo permanece. O mundo começa e acaba sem cessar; ele está a cada instante em seu começo e em seu fim; nunca houve nem jamais haverá outro. No imenso oceano de matéria nenhuma molécula se parece com outra, nenhuma molécula se parece consigo mesma. (Diderot, 1975, XVII, p. 128)

Doravante, a diferença penetra no indivíduo mesmo, e o fi- 
lósofo pode dizer sobre o Sobrinho: "Nada é mais dessemelhante dele do que ele mesmo", enquanto o caminhante parisiense observa: "Ide às Tuilleries e vereis ou aos Champs Elysées num dia de festa; considerai todas as mulheres que encherão as alamedas, e não encontrareis uma só que tenha os dois cantos da boca perfeitamente semelhantes" (Diderot, 1996, p. 1400).

A força dos devaneios de d'Alembert, posta em ação pela hipótese materialista de Diderot, é a de associar a dispersão dos elementos e a unidade do todo. Ela extrapola a multidão de gotas d'água para a imensidão do mar. Os indiscerníveis são reunidos a esta imagem do oceano, que atravessa toda a produção de Diderot. Imagem mais literária que vivida, já que ele só verá o mar pela primeira vez em 1773, a caminho de São Petersburgo. Nós a encontramos desde as notas da tradução do Ensaio sobre o mérito e a virtude. Shaftesbury fala do grande todo. Diderot assinala em nota: "no universo tudo está unido. Esta verdade foi um dos primeiros passos da filosofia, e foi um passo de gigante" (Diderot, 1975, I, p. 313). Mais à frente, Shaftesbury mistura fé numa ordem moral e prazer estético: "se a ordem e a beleza do universo forem os objetos de nossa admiração e de nosso amor, nossas afeições compartilharão a grandeza e a magnificência do assunto e a elegante sensibilidade pelo belo, disposição tão favorável à virtude, nos conduzirá até ao êxtase". Diderot reage em nota a esta última palavra e se deixa levar por um devaneio místico:

À medida em que o universo se estende aos olhos do filósofo, tudo o que o rodeia diminui. A terra desaparece sob seus pés. O que acontece com ele mesmo? Entretanto, ele sente um doce tremor nesta contemplação que o aniquila; depois de ter-se visto afogado, e, por assim dizer, perdido na imensidão dos seres, ele experimenta uma satisfação secreta em se encontrar sob os olhos da divindade. (Diderot, 1975, I, p. 359)

A imagem eufórica do afogamento parece estar nos antípodas 
de toda realidade fisiológica ${ }^{10} \mathrm{e}$, neste $z$ zoom vertiginoso do detalhe ao conjunto, Deus é aceito como um nome dado à unidade do grande todo.

Esse devaneio, que se poderia considerar deísta, não está longe da visão materialista do matemático Saunderson na Carta sobre os cegos. Saunderson, em seu leito de morte, recusa a doutrinação do religioso que veio lhe falar de Deus:

Oh, filósofos, transportai-vos pois comigo sobre os confins deste universo, para além do ponto em que toco e onde vedes seres organizados; passeai comigo sobre este novo oceano, e procurai através de suas agitações irregulares, alguns vestígios deste ser inteligente cuja sabedoria admirais! (Diderot, 1975, IV, pp. 51-52)

O êxtase diante da ordem universal se transforma numa consciência espantada diante da grande desordem cósmica. A mesma imagem do oceano pode ser extraída do lado da unidade ou então do lado de uma heterogeneidade movimentada. J.-C Bourdin fala de um "materialismo dos confins", atento aos limites e às passagens". Pouco tempo depois, Diderot redige um verbete de história da filosofia para a Enciclopédia, a chamada "Asiáticos (Filosofia dos)":

Deus é como um oceano imenso no qual se moveriam vários frascos cheios de água; os frascos, para qualquer lugar onde possam ir, estão sempre no mesmo oceano, na mesma água; e, vindo a se quebrar, a água que eles continham se encontraria ao mesmo tempo unida ao seu todo, a este oceano do qual elas eram porções. (Encyclopédie, I, p. 753).

10 Realidade evocada, por exemplo, por Ménuret de Chambaud que, no verbete "Pulso", da Enciclopédia, compara os maus médicos aos que se afogam: "semelhantes a essas pessoas que, prestes a se afogar, tentam, pela multiplicidade de seus movimentos, escapar de uma morte próxima: eles se debatem em vão; seus esforços, pouco moderados e mal dirigidos, não servem senão para enfraquecê-los, e a precipitá-los mais cedo" (Encyclopédie, XIII, p. 239).

11 Cf. Bourdin, 1998, p. 64. 
A imagem, desta vez, insiste sobre a unidade do Criador e das criaturas, sobre a imanência geral.

Uma tipologia das atitudes teóricas pede uma clara diferença teórica entre deísmo e ateísmo. Não é certo que a lógica da imagem permita estabelecê-la tão claramente. Na conclusão do último livro deixado inacabado por Diderot no final de sua vida, encontramos uma série de pensamentos soltos. Um dentre eles conta o desejo que temos de saber o que se dirá de nós depois de nossa morte. $\mathrm{O}$ defunto, embora devolvido à indistinção da matéria, se interessa pela imagem que deixou entre aqueles que lhe sobreviveram, pelos discursos sobre ele, por este último julgamento sem juiz supremo: “ É como um nadador que olha sua roupa de nadar sobre a margem. Homens que não se temem mais, o que haveis então escutado?" (Diderot, 1975, XVII, p. 516). Poderíamos ser tentados a ver na separação entre o nadador e sua roupa uma retomada da oposição entre a alma e o corpo; trata-se, ao contrário, do corpo e da lembrança que se guarda, ou do traço que ele deixa atrás de si, ou seja, também do homem e da ideia que ele tem de sua morte. A imagem do oceano pode ser interpretada de um ponto de vista interno como uma fusão mística com o todo, ou de um ponto de vista externo como uma margem com os destroços trazidos pela maré. Ela encontra uma força nova, ela é devolvida à sua violência inquietante nas pinturas de tempestade que Diderot admira tanto sob o pincel de Vernet ou de Loutherbourg. O afogamento como êxtase alterna com a distância sublime introduzida entre o naufrágio e olhar a partir da terra firme. O ponto de vista é ora interno ao grande todo, ora externo, sobre os confins: "Tudo o que espanta a alma, tudo o que imprime um sentimento de terror conduz ao sublime. Uma vasta planície não espanta tanto como o oceano agitado" (Diderot, 2008, p. 323). Jean-Claude Bonnet é sensível a esta imagem, à qual ele dá à última palavra de seu ensaio sobre Diderot:

Este êxtase, em sua grandeza pagã, qualifica um materialismo sem amargura. O último olhar de Diderot, agitado e sereno, tem uma elegante 
suavidade lucreciana, para além de tudo, de acordo com o movimento do mundo. Diderot deixa a porta aberta bater com os grandes ventos. Ele flutua, nadador morto e afogado pensativo: o materialismo o leva a um êxtase feminino. (Bonnet, 2013, p. 396).

Não nos banhamos jamais duas vezes no mesmo rio, mas somos levados para o mesmo oceano. Como a maneira pela qual as ciências observam e experimentam os casos particulares para arriscar leis gerais, o filósofo se encanta com a diversidade cintilante do mundo e sugere hipóteses globais sob o modo do sonho, da visão ou do paradoxo. Ele é materialista por sua recusa da hipótese divina e criacionista, mas a escolha das formas dialógicas ou descontínuas lhe permite evitar qualquer materialismo constituído, qualquer sistema da natureza. Duas questões ficam então em suspenso: a distinção entre coerência do pensamento ${ }^{12}$ e sistema, a articulação entre a opção materialista e as escolhas políticas ou morais.

\section{Referências bibliográficas}

BELAVAL, Y. "Sur le matérialisme de Diderot", Europäische Aufklärung, Munich, Wilhelm Fink, p. 9-21, 1967 [republicado em Études sur Diderot. Paris: PUF, p. 353-367].

BONNET, J.-C. Diderot: promenades dans l'ouvre. Paris: Le Livre de Poche, 2013 [reed.]

BOURDIN, J.-C. Diderot: le matérialisme. Paris: PUF, 1998.

DIDEROT, D. Euvres complètes. Edição de J. Fabre, H. Dieckmann, Jacques Proust, Jean Varloot. Paris: Hermann, 1975

12 É o termo ao qual de refere Colas Duflo em Diderot Philosophe (2013 reed.) e Diderot: du matérialisme à la politique (2013). 
DIDEROT, D. Euvres, t. IV. Éd. Laurent Versini. Paris: Robert Laffont, 1996 (Col. Bouquins).

. Diderot. Edição dirigida por Michel Delon. Paris: Gallimard, Col. Bibliothèque de la Pléiade, 2004 (v. I, Contes et romans); 2010 (v. II, Euvres philosophiques).

. Salons. Edição de Michel Delon. Paris: Gallimard, 2008.

DIDEROT, D .; D’ALEMBERT, J. Encyclopédie, ou dictionnaire raisonné des sciences, des arts et des métiers. 17 vols. Paris, 1751 -1765 .

DUFLO, C. Diderot Philosophe. Paris: Honoré Champion, 2003 [reeditado em 2013].

. Diderot: du matérialisme à la politique. Paris: Ed. CNRS, 2013.

FAUVERGUE, C. Diderot, lecteur et interprète de Leibniz. Paris: Honoré Champion, 2006.

FONTENAY, E. Diderot ou le matérialisme enchanté. Paris: Grasset, 1981.

D’HOLBACH. P. T. Système de la nature, 2 vols., Paris, 1770.

IBRAHIM, A. Diderot, un matérialisme éclectique. Paris: Vrin, 2010.

LEFEBVRE, H. Diderot. Paris: EFR, 1949 [reeditado como Diderot ou les affirmations fondamentales du matérialisme Paris: L'Arche, 1983].

LOJKINE, S. "Le matérialisme biologique du Reve de d'Alembert”. Littératures, n. 30, printemps 1994.

SURATTEAU-IBERRAKENS, A. "Diderot et la médecine, un matérialisme vitaliste?" Recherches sur Diderot et l'Encyclopédie, n. 26, 1999.

VENTURI, F. Jeunesse de Diderot (de 1713 à 1753). Paris: Albert Skira, 1939. 